\title{
CONSIDERAÇÕES SOBRE A LEGISLAÇÃO DO ENSINO E DO EXERCICIO DO TECNICO DE ENFERMAGEM E DO AUXILIAR DE ENFERMAGEM
}

\author{
* Taka Oguisso
}

\begin{tabular}{lll}
$/ 13$ \\
\hline
\end{tabular}

OGUISSO, T. - Consideraçōes sobre a legislação do ensino e do exercício do técnico de enfermagem e do auxiliar de enfermagem. Rev. Bras. Enf.; DF, 30 : 168-174. 1977.

\section{INTRODUÇAO}

O rápido desenvolvimento científico e tecnológico impōe contínuas modificaçōes em todas as áreas do conhecimento humano, em especial na área de saúde e, conseqüentemente, na enfermagem São muitos os fatores sócio-econômicos e culturais que atuam no sistema de ensino e de exercício da enfermagem exigindo análise, estudo e revisão de programas para o efetivo acompanhamento dessa evolução.

Dentre as funçōes educativas da enfermeira, tais como treinamento de pessoal para atividades de apoio em serviços de enfermagem, educação em serviço para atualização ou aperfeiçoamento dos profissionais, educação sanitária de pacientes ou familiares, palestras educativas para grupos de comunidade, há ainda o magistério de $1 .^{\circ}$ e $2 .^{\circ}$ graus, isto é, o preparo de Auxiliares de Enfermagem e de Técnicos de Eenfermagem. Para este último é exigida a formação pedagógica específica em curso de licenciatura em enfermagem (Portaria MEC n.o 13/69).

Alunos dos cursos de licenciatura em Enfermagem vêm tendo dificuldades em encontrar comentários, interpretaçōes e aplicações da legislação sobre o Técnico e o Auxiliar de Enfermagem.

Esses enfermeiros licenciados deveverão assumir as responsabilidades de ministrar as disciplinas profisionalizantes de ambos os cursos, Técnico e Auxiliar de Enfermagem e, dirigir ou coordenar essas escolas ou cursos.

O presente estudo analítico da legislação do ensino e do exercício do Técnico e do Auxiliar de Enfermagem, mesmo que, ainda, sem a profundidade desejável, pretende:

- Profesora assistente do Departamento de Orientação Profissional de Escola de Enfermagem da Universidade de São Paulo e Chefe de Equipe de Programas da Subdiretoria de Planejamento do INPS - SP. 
OGUISSO, T. - Consideraçōes sobre a legislação do ensino e do exercício do técnico de enfermagem e do auxiliar de enfermagem. Rev. Bras. Enf;; DF, 30 : 168-174. 1977.

a) apresentar a problemática da diversidade de formação do Auxiliar de Enfermagem; e,

b) alertar o pessoal docente de escolas ou cursos desses níveis sobre a necessidade de adequar os programas dentro das novas realidades.

\section{LEGISLAÇÃO DO ENSINO}

A legislação sobre o curso de Auxiliar de Enfermagem, regulada por força da Lei n. ${ }^{775}$, de 6 de agosto de 1949, vem sofrendo sucessivas alteraçōes, principalmente nos últimos dez anos, desorientando as diretoras dessas escolas ou cursos ou obrigand $\mathfrak{i}$-as a contínuas adaptações.

Por essa primeira legislação, o curso de Auxiliar de Enfermagem era um curso essencialmente profissionalizante e dirigido para a assistência curativa (Decreto $27.426 / 49$, art. 2 . $^{\circ}$.

O Curso Técnico de Enfermagem, criado em 1966, nas Escolas de Enfermagem Ana Neri e Luiza de Marillac, pelos Pareceres do Conselho Federal de Educação números 171/66 e 224/66, respectivamente, também já sofreu modificaçōes, apesar de existir há tão pouco tempo.

Ambos os cursos eram realizados com base em legislação própria, desvinculada do sistema de educação nacional.

Com efeito, a Lei n. ${ }^{\circ} 4.024$, de 20 de dezembro de 1961, que fixa as Diretrizes e Bases da Educação Nacional, somente previa no art. 47 e seu parágrafo único que "o ensino técnico de grau médio abrange os seguintes cursos: a) indústria; b) agrícola; c) comercial. Os cursos técnicos de nível médio não especificados nesta lei serão regulamentados dos diferentes sistemas de ensino".

A Portaria do Ministério da Educação e Cultura n. 106 , de 28 de abril de 1965, ainda vigente, dispõe sobre o curso de Auxiliar de Enfermagem, mas não fixa carga horária. Estabelece a idade minima de 16 anos para matrícula, discri- mina as disciplinas e estágios específicos e fixa a duração do curso em dois anos letivos de 180 dias cada um, trazendo como conseqüência grande diversidade no nível de ensino e, conseqüentemente, no preparo de profissionais.

Em 1970, o Parecer 75/70, do Conselho Federal de Educação, instituiu o curso intensivo de Auxiliar de Enfermagem em onze meses, exigindo como requisito para ingresso dos candidatos, a conclusão do curso ginasial e idade mínima ao redor dos 18 anos. Porém, antes que esse novo sistema pudesse ser efetivamente implantado por algumas escolas e avaliado, surgiu um nova lei de ensino que veio, mais uma vez, modificar a sistemática do curso de Auxiliar de Enfermagem. Foi a Lei n. ${ }^{0} 5.692$, de 11 de agosto de 1971, que fixa as Diretrizes e Bases para o Ensino de $1 .^{\circ}$ e $2 .^{\circ}$ graus.

Com o advento dessa nova lei, o curso Técnico de Enfermagem e o Curso de Auxiliar de Enfermagem passaram, real e efetivamente, a integrar o sistema educacional do país, ao nível de $2 .^{\circ}$ grau. A tônica constante em toda a nova Lei de Diretrizes e Bases para o ensino secundário ou de $2 .^{\circ}$ grau é a profissionalização, isto é, a "formação para o trabalho, no seu sentido de terminalidade e o preparo para o ensino superior, no sentido de continuidade".

Entretanto, a Professora Esther de Figueiredo Ferraz ao relatar o Parecer 2.713/74 da CE 1.0/2. ${ }^{\circ}$ graus, do Conselho Federal de Educação, possibilita "a título transitório e emergencial, face às condiçōes sócio-econômicas regionais ou locais, e para atender às exigências do mercado de trabalho, continuar a promover a formação do referido profissional (auxiliar de enfermagem) a nível de 1. "grau".

A colocação do curso de Auxiliar de Enfermagem na mesma faixa de ensino do Técnico, isto é, no $2 .^{\circ}$ grau, ou "a título transitório e emergencial" no $10^{\circ}$ 
OGUISso, T. - Consideraçōes sobre a legislação do ensino e do exercício do técnico de enfermagem e do auxiliar de enfermagem. Rev. Bras. Enf.; DF, 30 : 168-174. 1977.

grau, significa que a formação do auxiliar de enfermagem poderá ser feita:

a) ao nível das $5 .^{\mathrm{a}}$ e $6 .^{\mathrm{a}}$ séries do $1 .^{\circ}$ grau, em curso regular de dois anos letivos, de acordo com a Portaria MEC n. ${ }^{\circ}$ 106/65;

b) ao nível das 7. ${ }^{\mathrm{a}}$ e $8 .^{\mathrm{a}}$ séries do $1 .^{\circ}$ grau, em curso regular, também de dois anos letivos, conforme a mesma Portaria n.o 106/65;

c) em cursos intensivos de onze meses, após conclusão do $10^{\circ}$ grau, conforme fol possibilitado pelo Parecer do Conselho Federal de Educação 75/70;

d) em cursos regulares a nível de $2 .^{\circ}$ grau, de três anos de duração, constituindo "uma das habilitaçōes parcials ou menores ligadas à área da enfermagem";

e) em cursos supletivos de qualificação ou de habilitação profissional, comportando, nesse caso, diversas modalidades.

Além desses tipos de cursos de formação, há ainda a possibilidade do candidato se submeter a exame de supllência profissionalizante, podendo, se aprovado, receber o título de Auxiliar de Enfermagem.

O sistema supletivo, nos termos do Parecer 699/72, comporta quatro tipos ou funçōes básicas: suplência, suprimento, aprendizagem e qualificação. Essas modalidades podem ser desenvolvidas por meio de cursos e exames, abrangendo, de acordo com a Lei 5.692/71, "conforme as necessidades a atender, desde a iniciação no ensino de ler, escrever e contar, a formação profissional definida em lei específica até o estudo intensivo de disciplinas do ensino regular e atualização de conhecimentos" (art. 25). Dos quatro tipos, interessa à enfermagem a qualificação, que deve ser realizada fundamentalmente por meio de cursos e, não somente exames, com vistas à profissionalização. Atualmente não é permitido, no ensino regular, a profissionalização exclusiva sem educação geral, nem esta em caráter exclusivo sem profissionali- zação. A profissionalização em nível de 1. grau só é permitida em circunstâncias excepcionais, como ocorre com o curso de Auxiliar de Enfermagem, a nivel de $10^{\circ}$ grau, nos termos do já referido Parecer 2.713/74, do Conselho Federal de Educação.

Nos Estados da Federação, onde os respectivos Conselhos de Educação ainda não baixam atos regulando os cursos de Auxillar de Enfermagem, ou onde estes ainda não foram reorganizados nos termos da Lei 5.692/71, esses cursos poderão funcionar de acordo com a Portaria MEC 106/65 e Parecer CFE 75/70. Enquanto não houver normas próprias de regulamentação pelo sistema de ensino estadual, essas escolas ou cursos poderão continuar com o sistema anterior, e os títulos continuam a ter validade nacional.

Não há dúvida de que o curso Técnico de Enfermagem é curso de $2 .^{\circ}$ grau, pois desde o início foi situado nessa faixa e nessa faixa se mantém. $O$ ensino regular de $2 .^{\circ}$ grau conduz sempre à habilitação profissional, seja parcial ou plena. aqui que se diferenciam as duas categorias da enfermagem: o Auxiliar e o Técnico de Enfermagem.

O curso regular de $2 .^{\circ}$ grau, que conduz à habilitação parcial de enfermagem, com duração de três anos, leva à formação do Auxiliär de Enfermagem, conferindo certificado ao concluinte. $O$ curso que conduz à habilitação plena de enfermagem leva à formação do Técnico de Enfermagem, conferindo diploma ao concluinte.

Ambos os cursos, isto é, de habilitação parcial ou plena, podem ser realizados também pelo sistema supletivo. Nesse caso, há redução da duração do curso, mas a carga horária é a mesma dos cursos regulares, como também os títulos e os comprovantes de conclusão.

A amplitude de aplicação do sistema supletivo, permite, além da simples re- 
OGUISSO, T. - Consideraçōes sobre a legislação do ensino e do exercício do técnico de enfermagem e do auxiliar de enfermagem. Rev. Bras. Enf.; DF, $30: 168-174.1977$.

dução da duração do curso, a consecução dos objetivos por meio de exames ou cursos, sem obrigatoriedade de seqüência de graus, isto é, o segundo supondo o primeiro, etc.

Aproveitando-se a alternativa criada pelo Parecer $2.713 / 74$, pode ser proporcionada qualificação profissional de Auxiliar de Enfermagem a nível de $10^{\circ}$ grau. O concluinte desse curso, recebe certificado de Auxiliar de Enfermagem, de validade apenas regional, e não nacional.

O concluinte de cursos de $1 .^{\circ}$ grau que desejar habilitar-se rapidamente, para o exercício da profissão no campo da enfermagem, poderá fazê-lo também em cursos de qualificação profissional. $O$ currículo é composto apenas de disciplinas profissionalizantes e é conferido certificado de Auxilar de Enfermagem, com validade nacional, mas sem direito a prosseguimento de estudos em nível superior. Há ainda possibilidade desses candidatos prestarem exame supletivo de Técnico de Enfermagem, recebendo nesse caso, certificado de Técnico e não diploma. Por não terem concluído o $\mathbf{2}^{\circ}$ grau, podem exercer a profissão como Técnico, mas não podem prosseguir estudos em nível superior.

Já o concluinte do curso de educação geral de $2 .^{\circ}$ grau, pode fazer curso ou exame supletivo de habilitação profissional plena de enfermagem. Ao serem aprovados receberão diploma de Técnico de Enfermagem, com direito a prosseguimento de estudos em nivel superior.

O essencial é que, qualquer que seja o sistema, regular ou supletivo, em cursos de Técnico ou de Auxiliar de Enfermagem, os enfermeiros enfatizem o aspecto prático de desenvolvimento de habilidades profissionais e de atitudes éticas, e não tanto o acúmulo de conhecimentos teóricos. Recormenda-se que, para cada hora de aula teórica correspon- da um mínimo de duas ou três horas de prática profissional.

No Estado de São Paulo, a Deliberação do Conselho Estadual de Educação n. ${ }^{\circ}$ $14 / 75$, já criou o curso de habilitação parcial de auxiliar de enfermagem, no sistema de ensino regular ou supletivo, com carga horária mínima de 1.100 horas de conteúdo profissionalizante. Instituiu ainda, curso supletivo de Complementação da Habilitação Parcial "Auxiliar de Enfermagem" com vistas à obtenção da Habilitação Plena, com um mínimo de 300 horas. Assim, o portador de certificado de Auxiliar de Enfermagem, que comprovar conclusão da parte de educação geral do ensino de $2 .^{\circ}$ grau, por via supletiva ou regular, e completar o curso de complementação com 300 horas, poderá receber diploma de Técnico de Enfermagem.

Que repercussōes terá tão grande e indefinida abertura para o ensino ao nível do Auxiliar de Enfermagem?

O fato é que a ausência de diretriz oficial única desorienta cada vez mais os responsáveis por esses cursos. A possibilidade de formação de um mesmo profissional, ora em um nível, ora em outro, cria dubiedades que, certamente, refletirão no exercício profissional.

\section{LEGISLAÇAOO DO EXERCICIO PROFISSIONAL}

Os Serviços de Enfermagem das instituiçōes de saúde podem contar com três categorias distintas de profissionais de enfermagem: enfermeiros, técnicos de enfermagem e auxiliares de enfermagem, preparados em cursos formais integrados no sistema educacional do país.

A Lei n. 0 2.604, de 17 de setembro de 1955, que regula o exercício da enfermagem profissional, prevê, ainda, as seguintes categorias: obstetriz, enfermeiro prático ou prático de enfermagem e parteira prática. Além desses exercentes da 
OGUISSO, T. - Consideraçōes sobre a legislação do ensino e do exercício do técnico de enfermagem e do auxiliar de enfermagem. Rev. Bras. Enf.; DF, 30 : 168-174. 1977.

enfermagem, são encontrados, na prática, os atendentes, isto é, pessoas sem formação profissional, mas só com treinamento em serviço. Os atendentes não constituem categoria profissional definida na lei do exercício profissional. Porém, de acordo com o Levantamento de Recursos e Necessidades de Enfermagem, realizado pela Associação Brasileira de Enfermagem, em 1958, cujos dados são válidos ainda hoje, $70 \%$ das atividades de enfermagem sāo executadas por atendentes.

Por outro lado, na III Reuniāo Especial de Ministos da Saúde das Américas, realizada em Santiago, Chile, de 2 a 9 de outubro de 1972, foi elaborado o Plano Decenal de Saúde para as Américas. Nesse documento oficial, considerando a situação real da enfermagem, os Ministros recomendam "alcançar uma força de trabalho para a América Latina e Caribe, em 1980, que represente uma proporção de 19 elementos do pessoal de enfermagem por 10.000 habitantes. Desse grupo, 4,5 por 10.000 habitantes deverão ser enfermeiros". Recomendam, ainda, "intensificar a capacitação do pessoal de enfermagem a fim de preparar no decênio, 124.917 enfermeiros (dos quais $1 / 3$ poderá ser preparada a nível superior e $2 / 3$ a nível médio) e a $\mathbf{3 6 0 . 0 0 0}$ auxiliares de enfermagem".

Passando o Auxiliar de Enfermagem para a faixa de nível médio junto com os Técnicos de Enfermagem, e estes juntos com os enfermeiros, que categoria de enfermagem irá preencher os 4,5 por 10.000 habitantes, recomendado pelo Plano Decenal?

O pessoal formado atualmente existente no Brasil, de acordo com os dados de MEDEIROS (1975), coordenadora da Comissão de Documentação e Estudos da Associação Brasileira de Enfermagem, é de 13.724 enfermeiros, 1.341 técnicos de enfermagem e $\mathbf{3 0 . 8 7 8}$ auxiliares de enfermagem.
O Ministério da Saúde do Brasil, demonstrando sua visível preocupação com a problemática da enfermagem nacional e, procurando cumprir as Recomendaçōes do Plano Decenal de Saúde, vem promovendo estudos e programas para apoiar e fortalecer os sistemas de formação e capacitação de auxiliares de enfermagem necessários à demanda, no país, na década atual.

O "Relatório de Avaliação do ProjetoFormação de Auxiliares de Enfermagem" do Ministério da Saúde assegura que em "1980, o país contará com aproximadamente 16.000 graduados em Enfermagem, mantidas as atuais tendências de formação e de evasão. $O$ estoque estará, portanto, muito aquém das necessidades que, quanto a este profissional foram referidas no Plano Decenal de Saúde para as Américas, que indica proporção de 4,5 por 10.000 habitantes. Corresponde, em números absolutos, a 56.250 enfermeiros". Se for considerada a proporção de $1 / 3$ de pessoal de nível superior e 2/3 a nível médio, ou seja, de técnicos de enfermagem, haverá necessidade de 18.750 enfermeiros e 37.500 técnicos de enfermagem.

Ainda nos termos do referido Relatório do Ministério da Saúde, com relação ao Auxiliar de Enfermagem, "a situação da meta esperada para 1980, consoante as proposiçōes do Plano Decenal de Saúde, será de 4,5 por 10.000 habitantes, o que equivale a 181.000 auxiliares de enfermagem. Os estoques conhecidos atualmente, acrescidos, segundo hipóteses alternativas, dos fluxos de preparação e de evasão, faz prever que, no final da década o pessoal desta categoria profissional somará aproximadamente 60.000 , ou seja, cerca de 4,8 por 10.000 habitantes. Para atingir à meta proposta, há de capacitar, até o final da década, aproximadamente, 130.000 auxiliares de enfermagem". 
OGUISSO, T. - Consideraçōes sobre a legislação do ensino e do exercício do técnico de enfermagem e do auxiliar de enfermagem. Rev. Bras. Enf.; DF, 30 : 168-174. 1977.

Que repercussões poderão fazer para o exercício profissional esta preocupação voltada apenas para capacitação de maior número de profissionais de nível médio no menor prazo possível?

Se o Técnico e o Auxiliar de Enfermagem, perante a legislação de ensino, ocupam a mesma faixa, como se fará a definição e delimitação de suas atribuiçōes na prática?

A regulamentação do exercício profissional do Técnico de Enfermagem ainda não ocorreu, apesar de as primeiras turmas terem se formado em 1968. A Lei $\mathrm{n}^{\circ} 2.604 / 55$, do exercício profissional, bem como o Decreto $50.337 / 61$, que a regulamenta, nada dispõem sobre o nível técnico, cujo aparecimento é posterior à lei. O Projeto de Lei n. ${ }^{\circ}$ 2.334/70 que regularia as atribuições do Técnico de Enfermagem não foi aprovado.

Uma nitida e perfeita delimitação de atividades profissionais é condição para evitar muitos problemas, conflitos, querelas e até reivindicações judiciais. Serão os enfermeiros, militantes em hospitais e serviços de saúde pública, que irão se defrontar com esses problemas. Como irão resolvê-los?

\section{CONSIDERAÇÓES FINAIS}

E certo que indefiniçōes no ensino terão reflexos no exercício profissional. mister, pois, adequar o programa de ensino às necessidades do exercício. Cabe ac enfermeiro, como líder da equipe de enfermagem, enfrentar os problemas e procurar resolvê-los. Mas, como fará isso ante à indistinção existente entre as categorias dos exercentes da enfermagem? A educação geral será suficiente para diferenciar funçōes técnicas? RIBEIRO (1974) também pergunta: "Estarão os hospitais com possibilidade de sustentar o salário de nível de $2 .^{\circ}$ grau para 0 maior contingente de pessoal de enfermagem? Não corremos o risco de voltar ou permanecer na solução "Atendente"? Haverá distinção entre o Auxiliar de Enfermagem e o Técnico de Enfermagem? A cultura geral justifica diferenciação de funçōes técnicas? O compromisso de formar mais 150.000 auxiliares de enfermagem até 1980 não será negado?"

Daí a urgência da aprovação de nova lei do exercício profissional em substituição à Lei n.o 2.604/55, já superada. O Conselho Federal de Enfermagem, em boa hora, está ultimando estudos e providências nesse sentido.

Mas, ainda cabe a nós, enfermeiros, individualmente, observar e estudar, no campo hospitalar, de saúde pública ou outro, as atividades da equipe de enfermagem. necessário estabelecer critérios para uma distribuição adequada de tarefas. Isso significa que devemos dividir proporcionalmente as diversas categorias de pessoal nos diferentes turnos de trabalho, de modo a poder estabelecer uma nítida delimitação de atribuições.

Para os enfermeiros que estão no campo do ensino, é mister lembrar que a formação, tanto do Auxiliar de Enfermagem como do Técnico de Enfermagem, deve ser feita basicamente no campo de estágio, e não em sala de aula. Cabe, ainda, desenvolver estudos e análises da legislação de ensino pertinente, ajustando à realidade e propondo medidas para a correta adequação às necessidades.

\section{REFERENCIAS BIBLIOGRAFICAS}

1 - ABEn - Levantamento de Recursos e Necessidades de Enfermagem no Brasil, 1957-58, mimiografado.

2 - ABEn - Seção de São Paulo - Boletim Informativo Paulista - Editorial de setembro de 1974.
3 - MEDEIROS, N. R. D. - Relatório da Comissão de Documentação e Estudos 1974/75, Revista Brasileira de Enfermagem, 28(3) : 85-109, jul.-set. de 1975. 
OGUISSO, T. - Consideraçōes sobre a legislação do ensino e do exercício do técnico de enfermagem e do auxiliar de enfermagem. Rev. Bras. Enf.; DF, 30 : 168-174. 1977.

4 - MEC - Conselho Federal de Educação - Parecer 2.713, nível de formação do Auxiliar de Enfermagem, após promulgação da Lei número 5.692/71 - Revista Brasileira de Enfermagem, 27(4): 532-548, outdez. de 1974.

5 - MEC - CE de $10^{\circ}$ e $2 .^{\circ}$ graus - Parecer 699/72, Documenta, ( ): 302-337. 1972.

6 - Ministério da Saúde - Fundação Serviço de Saúde Pública, Enfermagem - Legislação e assuntos correlatos, 3. ${ }^{\mathrm{a}}$ ed., Rio de Janeiro, 1974 3v.

\author{
7 - Ministério da Saúde - Secretaria de \\ Saúde Pública - DNOS - Rela- \\ tório de Avaliação do Projeto - \\ Formação de Auxiliar de Enferma- \\ gem, Rio de Janeiro, 1974. \\ 8 - OPS/OMS - Plan Decenal de Salud \\ para las Americas - Informe final \\ de la III Reunión Especial de Mi- \\ nistros de Salud de las Americas, \\ Documento Oficial n. ${ }^{\circ} 118$, enero \\ de 1973. \\ 9 - Secretaria da Educação - Estado de \\ São Paulo, Deliberação n. $.^{\circ} 14 / 75$, \\ D.O. de 14-6-75, págs. $16 / 17$.
}

